\title{
Article \\ Monothetic Analysis and Response Surface Methodology Optimization of Calcium Alginate Microcapsules Characteristics
}

\author{
Joshua Anani ${ }^{1}{ }^{\mathbb{D}}$, Hussien Noby ${ }^{1,2}$, Abdelrahman Zkria ${ }^{3,4}$, Tsuyoshi Yoshitake ${ }^{3}$ and Marwa ElKady ${ }^{1,5, *}$ \\ 1 Chemical and Petrochemicals Engineering, Egypt-Japan University of Science and Technology, \\ Alexandria 21934, Egypt; joshua.anani@ejust.edu.eg (J.A.); hussien.badry@ejust.edu.eg (H.N.) \\ 2 Materials Engineering and Design, Faculty of Energy Engineering, Aswan University, Aswan 81528, Egypt \\ 3 Department of Applied Science for Electronics and Materials, Kyushu University, Kasuga 816-8580, Japan; \\ abdelrahman_zkria@kyudai.jp (A.Z.); yoshitake.tsuyoshi.913@m.kyushu-u.ac.jp (T.Y.) \\ 4 Department of Physics, Faculty of Science, Aswan University, Aswan 81528, Egypt \\ 5 Fabrication Technology Department, Advanced Technology and New Materials Research Institute (ATNMRI), \\ City of Scientific Research and Technology Applications, Alexandria 21934, Egypt \\ * Correspondence: marwa.elkady@ejust.edu.eg
}

check for

updates

Citation: Anani, J.; Noby, H.;

Zkria, A.; Yoshitake, T.; ElKady, M. Monothetic Analysis and Response Surface Methodology Optimization of Calcium Alginate Microcapsules Characteristics. Polymers 2022, 14, 709. https://doi.org/10.3390/ polym14040709

Academic Editors: Chih-Wei Chiu, Chih-Chia Cheng and Jia-Wun Li

Received: 26 December 2021

Accepted: 31 January 2022

Published: 12 February 2022

Publisher's Note: MDPI stays neutral with regard to jurisdictional claims in published maps and institutional affiliations.

Copyright: (C) 2022 by the authors. Licensee MDPI, Basel, Switzerland. This article is an open access article distributed under the terms and conditions of the Creative Commons Attribution (CC BY) license (https:// creativecommons.org/licenses/by/ $4.0 /)$.

\begin{abstract}
Owing to bio-polymer's low-cost, environmental friendliness and mechanically stable nature, calcium alginate microcapsules have attracted much interest for their applications in numerous fields. Among the common production methods, the Electrospraying technique has shown a great potential due to smaller shape capsule production and ease of control of independent affecting parameters. Although one factor at a time (OFAT) can predict the trends of parameter effect on size and sphericity, it is inefficient in explaining the complex parameter interaction of the electrospray process. In the current study, the effects of the main parameters affecting on size and sphericity of the microcapsules using OFAT were optimized to attain calcium alginate microcapsules with an average diameter below $100 \mu \mathrm{m}$. Furthermore, we propose a statistical model employing the Surface Responses Methodology (RSM) and Central Composite Design (CDD) to generate a quadratic order linear regression model for the microcapsule diameter and sphericity coefficient. Experimentally, microcapsules with a size of $92.586 \mu \mathrm{m}$ and sphericity coefficient of 0.771 were predicted and obtained from an alginate concentration of $2.013 \mathrm{w} / \mathrm{v}$, with a flowrate of $0.560 \mathrm{~mL} / \mathrm{h}$, a needle size of $27 \mathrm{G}$ and a $2.024 w / v$ calcium chloride concentration as optimum parameters. The optimization processes were successfully aligned towards formation of the spherical microcapsules with smaller average diameter of less than $100 \mu \mathrm{m}$, owing to the applied high voltage that reached up to $21 \mathrm{kV}$.
\end{abstract}

Keywords: biopolymer; electrospraying; calcium alginate; surface responses methodology; microcapsules

\section{Introduction}

Alginate is a broad definitive term for a group of naturally occurring unbranched polysaccharides consisting of 1.4 linked $\beta$-D-mannuronic acid, a C-5 epimer and an Lguluronic acid. It is abundant in nature and mainly produced from seaweed, bacteria and algae, with around 30,000 metric tons of annual production [1]. Due to their abundance and versatility in application, alginates have seen significant applications as beads [2], fibers [3] and capsules of micro and nano sizes [4] in diverse fields ranging from biological and medical to chemical and mechanical use. In delivery systems, alginates have found an abundance in application due to their environmentally friendly nature, solubility in water, excellent biodegradability and compatibility [5]. Spherical hydrogel capsules and beads of alginates have been used widely for drugs, enzymes and cell delivery in the medical and biomedical sciences. Hydrogel Micro and nano alginate capsules have also gained recent popularity as an encapsulating material for anti-corrosion materials [6,7]. Alginate beads have a wide range of applications as encapsulating anti-corrosion materials due to 
their ease of use, low cost, lack of toxicity, mechanical stability and resilience to acidic and basic environments [8].

The primary alginate micro and nanocapsules production techniques are extrusion and emulsification/gelation. External extrusion techniques are the most popular, due to their simplicity of application and particle size distribution control [9]. However, the internal emulsification/gelation technique has the advantage of producing smaller capsule sizes $[10,11]$. A less common technique for producing alginate capsules is the spray drying technique. Typically, a mixture of alginate solution and organic reagents is atomized by hot airflow. The shortcoming of this technique is the product loss to the drying chamber walls and the loss of finer particles $(<2 \mu \mathrm{m})$ as exhaust air [12]. The aforementioned techniques are essential to producing alginate capsules as carriers for anti-corrosion agents in selfhealing coatings. Typically, alginates are available in commercial quantities as salts of sodium alginic acid and gum, although other salts of alginates are available.

The general preparation of alginate microcapsules involves ionic gelation of alginate, which comprises simple diffusion and crosslinking process with divalent cations, typically $\mathrm{Ca}^{2+}$ [13]. Calcium salts are used for crosslinking as they are economical, safe and easy to use. The alginate gelation occurs when the divalent cation binds itself to two carboxyl groups of an alginate molecule, as thoroughly documented and explained by the egg-box model [14]. The size, sphericity and shape of the capsules play a crucial role in the field of application of the polymer. Smaller-sized and spherical microcapsules are crucial as encapsulating materials for anti-corrosion materials in self-healing applications. The capsule's resistance to shear and compressive pressures increases as its size decreases [15]. Excellent shear and compressive forces are essential to controlled release in self-healing for anticorrosion. Smaller capsules can provide significant solid-liquid interface gaps in a given volume, facilitating substrate and product mass transfer $[16,17]$ Alginate sphericity also has a direct correlation with chemical and mechanical stability. Spherical capsules have shown remarkable and more effective gel strength than non-spherical ones. Premature encapsulant burst and release are also due to tears, cracks and breakages of non-spherical capsules [18].

The extrusion technique for alginate microcapsules involves forcing alginate solutions as droplets into the crosslinker through a nozzle. Extrusion is usually associated with larger alginate beads, usually of sizes $>1000 \mu \mathrm{m}$. However, the electrospray/electrodynamic atomization technique can produce smaller-sized microcapsules [19].

Electrospraying/electrodynamic atomization has seen recent advancements in the production of microcapsules in a more controlled manner. This technique uses electrostatic forces to overcome polymer surface tension and viscosity, extruding the fluid through a needle tip. In the presence of an electric potential, the extruding polymer, a conicalshaped micro or milli-sized droplet, accelerates as streams towards a crosslinking solution at the bottom where it is collected [20]. Various factors affect the size and sphericity production of the microcapsule; such as needle size, alginate concentration, electric potential and flowrate [21].

The emulsification technique is a small size-oriented technique for alginate microcapsule production [22]. In this technique, alginate solution is mixed with a suspension of insoluble calcium salts for gelation with a surfactant in an oil phase. An acid or a base adjusted the $\mathrm{pH}$ of the solution to guarantee complete gelation. Homogenization, stirring and sonication all influence the size reduction of the alginate microcapsule.

There have been several (OFAT) analyses of the effects of different variables on particle size and sphericity. However, OFAT analyses are inconclusive, and cannot explain the behaviors of the independent variables at some range of studies. Calcium alginate microcapsules have been optimized using response surface methodology $[19,21]$ in prior studies. However, the range of study for the respective parameters was limited, especially for flowrate and voltage.

Herein, this study investigated OFAT experiments for the independent parameters at a wider range of high voltage and flowrate, showing the inconsistencies of the OFAT. Accordingly, the introduction of a linear regression model and an ANOVA study were 
investigated to explain the parameter interactions and how they affect size and sphericity as an attempt to formulate microcapsules with smallest average diameter below $100 \mu \mathrm{m}$.

\section{Materials and Methods}

\subsection{Materials}

Low viscosity $(1 \% W / V, 5.5+/-2.0 \mathrm{cps})$ sodium alginate $\left(\mathrm{C}_{6} \mathrm{H}_{9} \mathrm{NaO}_{7}\right)$ was purchased from Advent ChemBio PVT. Ltd, India. Calcium chloride 2-hydrate $\left(\mathrm{CaCl}_{2} \cdot 2 \mathrm{H}_{2} \mathrm{O}\right)$ salt was purchased from AppliChem $\mathrm{GmbH}$, Germany.

\subsection{Synthesis of Calcium Alginates Using Electrospray Technique}

Various Sodium alginate solutions were made by dissolving sodium alginates in distilled water with the aid of a high-speed homogenizer. The solutions were left overnight for complete degassing. Each solution was poured into a $12 \mathrm{~mL}$ syringe with a blunted stainless needle of varying diameters. The filled syringes were inserted into the electrospray device's pump, with the needle tip kept at a consistent distance $(8 \mathrm{~cm})$ from the collecting beaker. The sodium alginate polymer solution was supplied at varying flow rates into a beaker containing the crosslinking calcium chloride solution. A varying high voltage was applied to the tip of the needle. The calcium chloride solution was placed on a stirrer at a constant rpm of 150, and grounded using crocodile connector clips. The microcapsules collected into the crosslinker were washed thoroughly after allowing it to harden for $2 \mathrm{~h}$. The blank microcapsules were dried in a vacuum oven at $50{ }^{\circ} \mathrm{C}$ overnight. Figure 1 is a representation of the electrospray process.

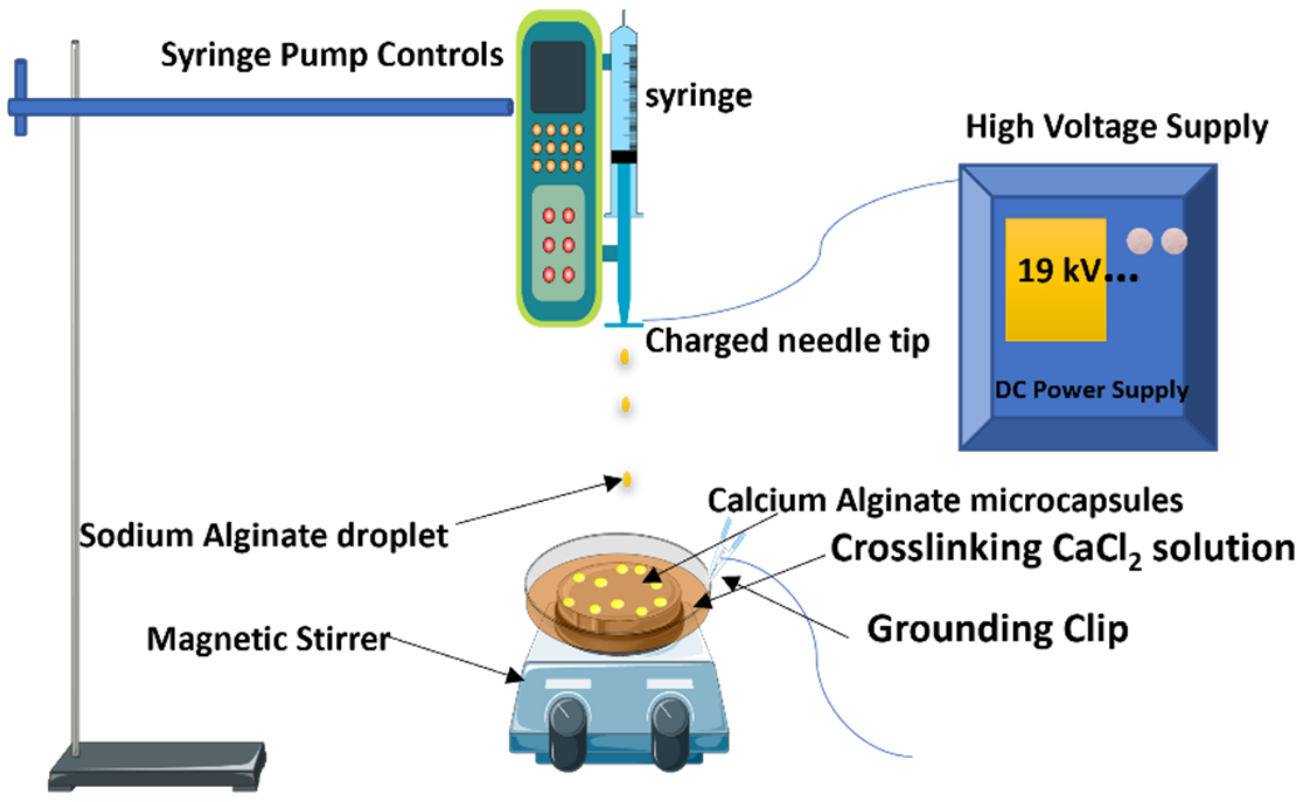

Figure 1. Elecrospray System Setup.

\subsection{Microcapsule Size Distribution Determination}

The different microcapsules produced by the electrospray technique were measured and analyzed using SEM (JEOL JSM-6390. Approximately 25 samples of the alginate microcapsules were selected and analyzed for each parameter combination and variation. The average minimum and maximum diameter were calculated from randomized samples using ImageJ software [19].

\subsection{Sphericity Coefficient Determination}

Different sphericity indicators have been used to determine the shapes of microcapsules and other minuscule structures [18,19]. 
For this study, the sphericity coefficient is preferred for calculating the average sphericity of the capsules for each parameter variation. It is calculated as illustrated in Equation (1).

$$
\text { Sphericity coefficient }=\frac{D_{L}}{D_{F}}
$$

$\mathrm{D}_{\mathrm{L}}$ is the lateral diameter and $\mathrm{D}_{\mathrm{F}}$ is the mean frontal diameter of the capsule at varying positions. Sphericity of 1 indicates a perfect sphere, while sphericity approaching infinity indicates elongation, such as fibers.

Overall, the average sphericity coefficient was calculated from 25 random samples for each parameter variation run.

\subsection{Experimental Size and Sphericity Optimization}

The size and sphericity of the electrosprayed microcapsules were optimized with Design-Expert software (Stat-Ease, version 13.0.0) using a response surface methodology (RSM) and a central composite design (CDD). Rather than making a monothetic one-factorat-a-time (OFAT) observation, the RSM employs statistical and mathematical approaches to study the interrelationship between independent factors and the desired response. After inputting the respective minimum and maximum independent factors from the responses collected from the diverse experimental runs generated by the software, a linear regression model was generated, employing quadratic process orders for subsequent response prediction. The equation for the quadratic model is illustrated in Equation (2)

$$
Y=\beta_{o}+\sum_{a=1}^{K} \beta_{a} X_{a}+\sum_{a=1}^{K} \beta_{a a} X_{a}^{2}+\sum_{a=1}^{K-1} \sum_{b=a+1}^{K} \beta_{a b} X_{a} X_{b}+\varepsilon
$$

where $Y$ is the dependent variable; $X_{a}$ and $X_{b}$ are the independent variables; $\beta_{o}$ is the overall average response constant/intercept; $\beta_{\mathrm{a}}$ is the coefficient of the linear regression model on a linear level; $\beta_{\mathrm{aa}}$ is the effect of squaring the linear coefficient; $\beta_{\mathrm{ab}}$ is the effect of the interrelationship between the coefficients of the linear regression; and $\varepsilon$ accounts for the error in the model.

Overall, the model was created with a single full block, resulting in 50 trials, calculated from the CCD model using Equation (3)

$$
\mathrm{N}=2^{\mathrm{K}}+2 \mathrm{~K}+\mathrm{n}
$$

where $\mathrm{K}$ is the independent variables studied and $n$ is the center points. The factor and response summary tables are stated in Tables 1 and 2.

Table 1. Experimental Independent Parameters.

\begin{tabular}{ccccc}
\hline Factor & Name & Units & Coded Low & Coded High \\
\hline $\mathrm{A}(\mathrm{X} 1)$ & $\begin{array}{c}\text { Sodium alginate } \\
\text { concentration }\end{array}$ & $\%$ & 2.00 & 6.00 \\
\hline $\mathrm{B}(\mathrm{X} 2)$ & Flowrate & $\mathrm{mL} / \mathrm{h}$ & 0.50 & 50.00 \\
\hline $\mathrm{C}(\mathrm{X} 3)$ & Needle size & $\mathrm{G}$ & 21.00 & 27.00 \\
\hline $\mathrm{D}(\mathrm{X} 4)$ & Voltage & $\mathrm{kV}$ & 13.00 & 21.00 \\
\hline $\mathrm{E}(\mathrm{X} 5)$ & $\begin{array}{c}\text { Calcium } \\
\text { chloride } \\
\text { concentration }\end{array}$ & $\%$ & 2.00 & 6.00 \\
\hline
\end{tabular}


Table 2. Response Parameters.

\begin{tabular}{ccccccccc}
\hline Response & Name & Units & Observations & Minimum & Maximum & Mean & Std. Dev. & Ratio \\
\hline R1 & Microcapsule diameter & $\mu \mathrm{m}$ & 50.00 & 75.253 & 1193.15 & 523.87 & 326.21 & 15.86 \\
\hline R2 & sphericity coefficient & N/A & 50.00 & 0.29632 & 0.9956 & 0.7731 & 0.1865 & 3.36 \\
\hline
\end{tabular}

The ANOVA (Analysis of Variance), model regression, optimization, numerical and graphical assessment of the bead size and sphericity were studied.

\subsection{Model Validation}

Post-analysis model confirmation was done for the predicted optimized microcapsule diameter and sphericity conditions. Greater priority was given to the microcapsule size, at the expense of sphericity. The microcapsule diameter was set to a minimum with a 5-star importance level in the prediction. The minimum sphericity coefficient was set at 0.7 , and the maximum at 0.99 . The desired outcome was the smallest possible diameter less than $100 \mu \mathrm{m}$, with appreciable sphericity.

\subsection{Optimization}

The optimization for the microcapsule diameter and sphericity was conducted using Design-Expert Software. The microcapsule diameter received more attention compared to the sphericity. The independent variables were given equal significance in the optimization process.

\section{Results}

\subsection{OFAT Analysis of Independent Parameters}

In order to fabricate sodium alginate microcapsules with smallest diameter and acceptable degree of sphericity, the effect of fabrication parameters on capsule size and sphericity were investigated experimentally using an OFAT analysis.

\subsubsection{Effect of Sodium Alginate Concentration}

There was an increase in the particle size as the concentration of electrosprayed sodium alginate solution increased from $2 \%$ to $6 \% w / v$, as denoted in Figure 2a. An increase in concentration leads to an increase in viscosity, and thus the extrusion of thicker fluid through the nozzle of the needle $[23,24]$. Figure 2 shows the distribution of microcapsule size with varying alginate concentrations. The $6 \% w / v$ microcapsules produced from the electrospray technique were elongated and misshapen due to increased surface tension at the needle-droplet surface, and as such, complexity in breaking off the viscous fluid at the needle tip $[18,19]$. Alginate sphericity decreased with increasing concentration. The higher viscosity of the solution could cause deformation of the microcapsule as it is electrosprayed into the crosslinking solution. Two forces act on an electrosprayed microcapsule as it moves from the tip of the needle into the crosslinker: the viscous forces and drag forces. The viscous force of the fluid seeks to maintain the microcapsule's form, while the drag force seeks to disrupt it [18]. As such, a very low concentration of the sodium alginate solutions (below $2 \% w / v$ ) that formed microcapsules had weaker walls, which were disrupted either in the crosslinker or during drying. On the other hand, the higher concentration alginate solution formed a sperm-like shape-a result also observed in another study [25], as also seen in Figure 2c. However, the interaction of other parameters, such as bigger needle size, could lead to spherical microcapsules at higher alginate concentrations.

\subsubsection{Effect of Voltage}

The effect of applied voltage at the electrospraying process is a critical parameter in the microcapsule size variation. During electrospraying, the surface tension of the sodium alginate polyelectrolyte solution becomes equal to the Coulomb repulsion forces at the extruded jet point when pushed through a needle with an electric voltage [26]. The fluid 
at the needle's tip creates a cone shape, referred to as the Taylor cone. Tiny droplets are sprayed spontaneously from the tip of the Taylor cone into a counter electrode when the electric field strength is greater than the balancing point. The development of a Taylor cone is critical for generating microcapsules [27], and heavily depends on operating parameters such as voltage and feed rate. A droplet on the tip of a needle develops, until it is heavy enough to escape the surface tension of the needle-droplet interface in the absence of an electric field, using the effect of gravity and the flow rate. At a higher voltage $(>21 \mathrm{kV})$, it was investigated that due to hydrodynamic instabilities, a narrow jet from the tip of the cone splits into multiple jets, resulting in unstable stream formation, fibers and non-uniformed capsule formation. The capsule sizes formed from lower voltages $(<13 \mathrm{kV})$ were too large for this investigation. Very spherical microcapsules were formed at a lower voltage.
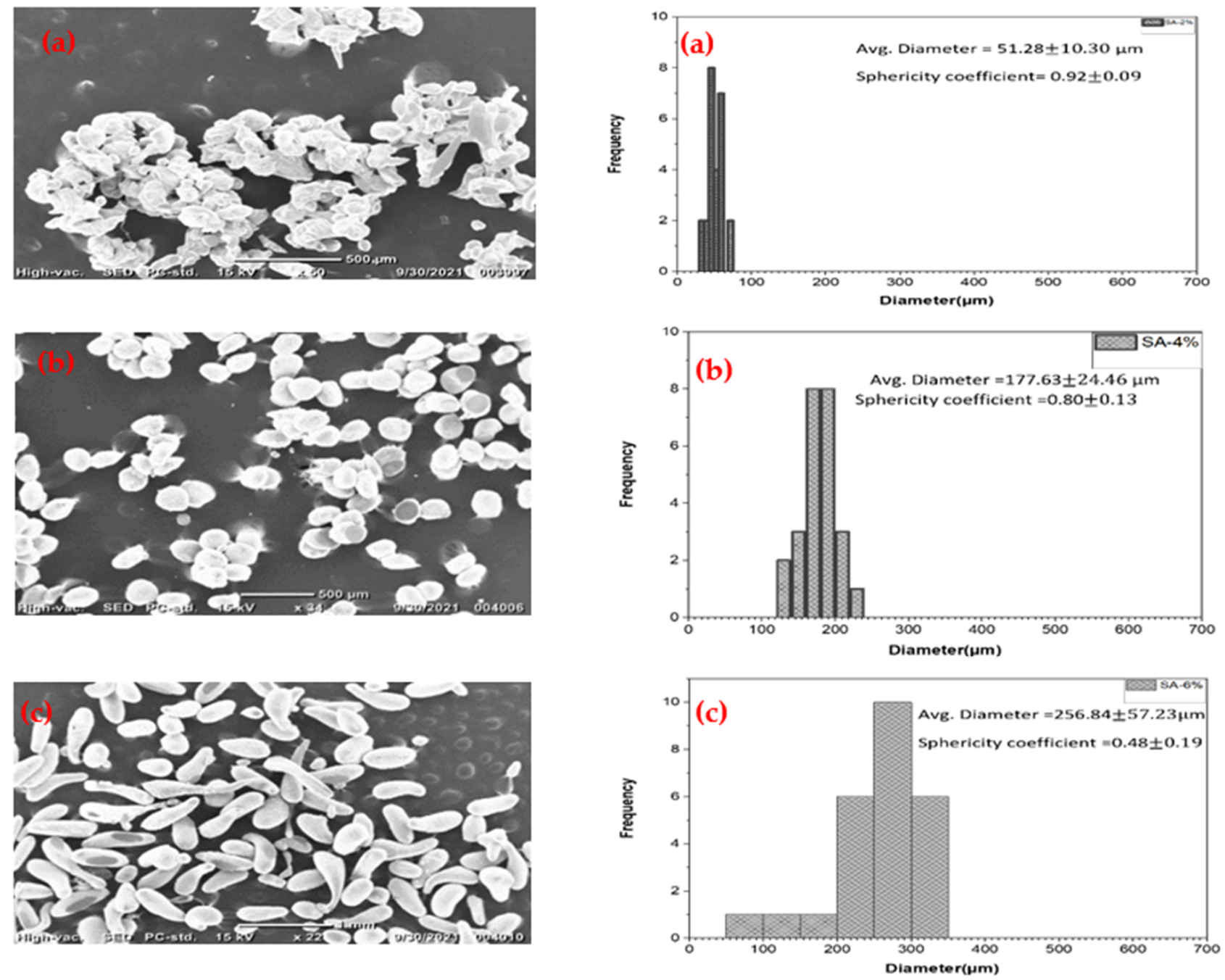

Figure 2. Monothetic analysis, SEM and distribution of 25 randomly selected Calcium alginate Microcapsules with varying Sodium Alginate concentrations (a) $2 \% w / v$; (b) $4 \% w / v$; (c) $6 \% w / v$.

\subsubsection{Effect of Flowrate}

Flowrate typically has an inverse relationship with microcapsule size and sphericity. In Figure $3 \mathrm{~d}-\mathrm{f}$, lower flowrates formed smaller-sized and better spherical microcapsules as compared to higher flowrates. The capsule size increases gradually and sphericity decreases gradually with increasing flowrates. However, the trend changes at higher flowrates in Figure $3 a-c$, as size starts to decrease while sphericity continues to reduce. This observation could be due to the interaction of parameters at high flowrates, causing size changes. A high flow rate increases the size of the droplets at the nozzle, lowering 
the surface charge density and increasing the capsule diameter [28]. When the flow rate increases, the sphericity decreases significantly, as there is no time to properly construct a Taylor cone at the tip of the needle. As a result, tear-shaped, pear-shaped and elliptical capsules develop. At very high flowrates, inconsistencies in trends were observed.
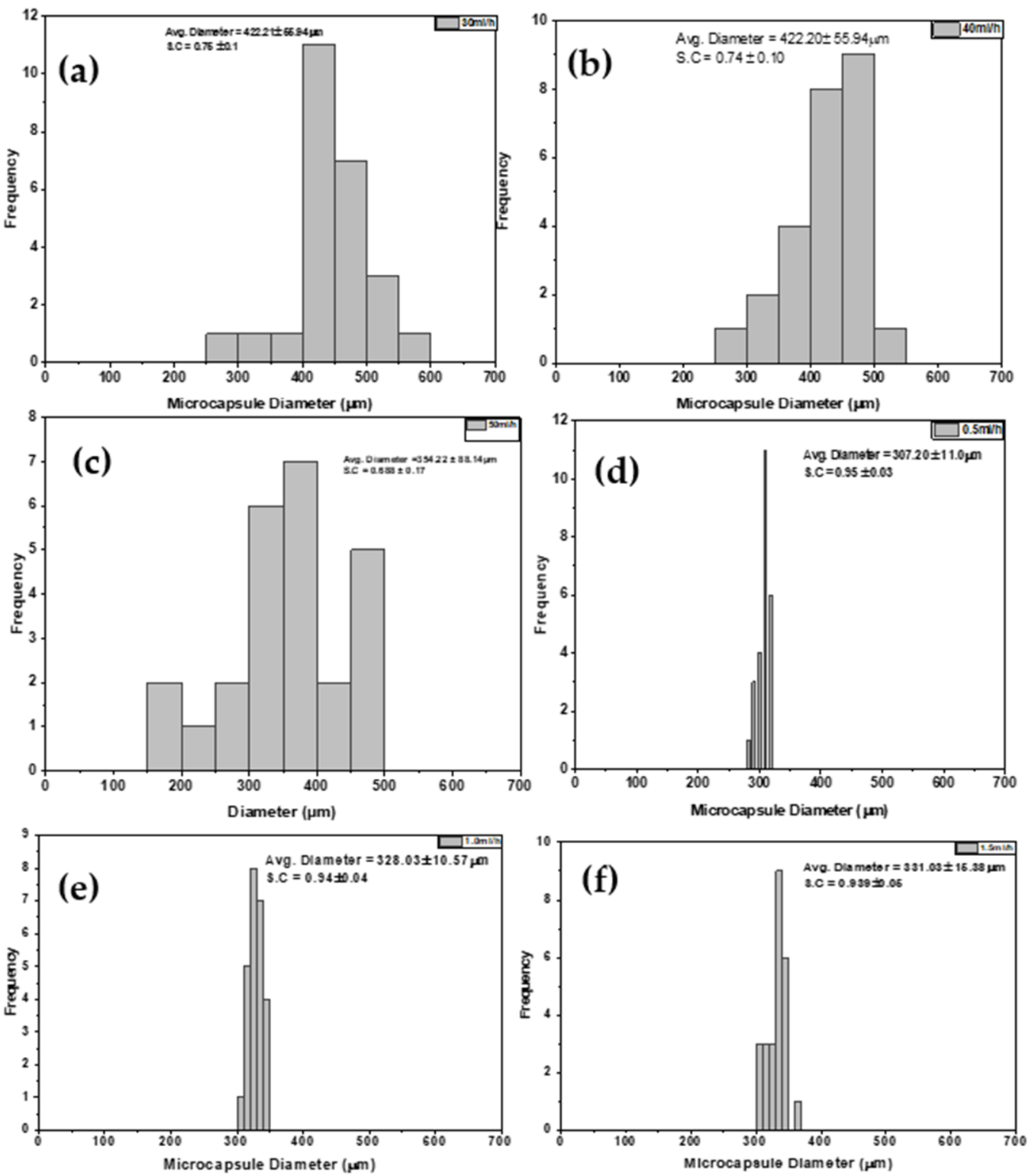

Figure 3. Microcapsule size distribution of calcium alginates electrosprayed at high (a-c) and low flowrates (d-f).

\subsubsection{Effect of Calcium Chloride Concentration}

Calcium chloride concentration has an inverse effect on the particle sizes of formulated sodium alginate microcapsules. The higher the calcium chloride concentration, the higher the shrinkage of the microcapsules produced, and therefore, the smaller the particle size [24]. However, the sphericity coefficient reduces with increasing concentration, as the microcapsules are hardened disproportionately, leading to smaller yet non-spherical particles. Microcapsules made from $<2 \% w / v \mathrm{CaCl}_{2}$ solution failed to harden, had weak walls and imploded, owing to inadequate crosslinker and hardening salt concentrations to produce stable microcapsules. From Figure 4 , the $6 \% w / v$ calcium chloride microcapsules showed a smaller average particle size, with sporadic distribution indicating 
polydispersity and an overall poor average sphericity coefficient. The $2 \% w / v$ showed a larger average particle size fractionally, but with an impressive sphericity coefficient and a better-monodispersed range. Most of the $2 \%$ microcapsules were similar to the $4 \% w / v$ microcapsules, except for some outliers. The outliers of the $2 \% w / v$ microcapsules are few enough to be included in the margin of error. The sphericity coefficient also favored the $2 \% w / v$ concentration microcapsules. The effect of calcium chloride as an independent parameter had little significance on the overall bead diameter compared to other strong parameters, such as voltage, needle size and alginate concentration.

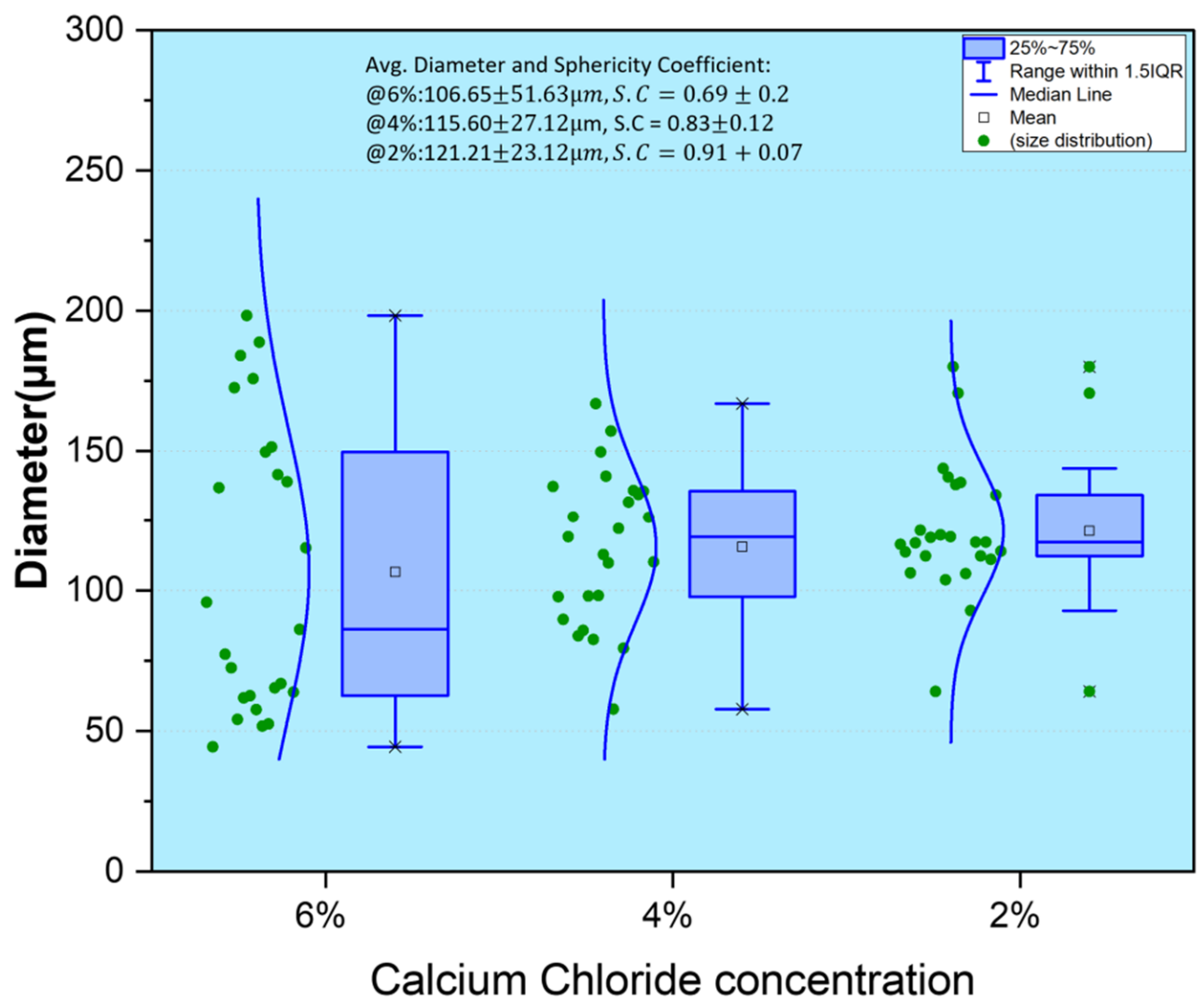

Figure 4. Box and Whiskers plot of the monothetic analysis of 25 randomly selected calcium alginate microcapsules crosslinked with varying concentrations of Calcium Chloride.

\subsubsection{Effect of Needle Size}

Needle size has a direct relationship with formulated calcium alginate microcapsule size. The smaller the orifice of extrusion, the smaller the microcapsule extruded [29]. As illustrated in Figure 5, two-needle sizes (21 and $27 \mathrm{G}$ ) were studied with all other parameters constant. The $27 \mathrm{G}$ needle performed better than the $21 \mathrm{G}$ needle, with a smaller particle size with a mean diameter of $157.63 \mu \mathrm{m}$ as compared to the $27 \mathrm{G}$ needle, which had a size of $237.37 \mu \mathrm{m}$. Overall, both showed a good distribution. Needle size is the most important parameter in diameter control [19]. The orifice of the needle controls the amount of fluid that flows to the surface of the needle. Therefore, the amount of alginate at the tip of the needle is controlled by needle size. The droplet at the tip is then acted on by voltage to reduce the size. The extent of reduction in diameter of the alginate droplet at the tip by voltage is dependent on the size of the polymer droplet supplied to the tip by the needle orifice. 

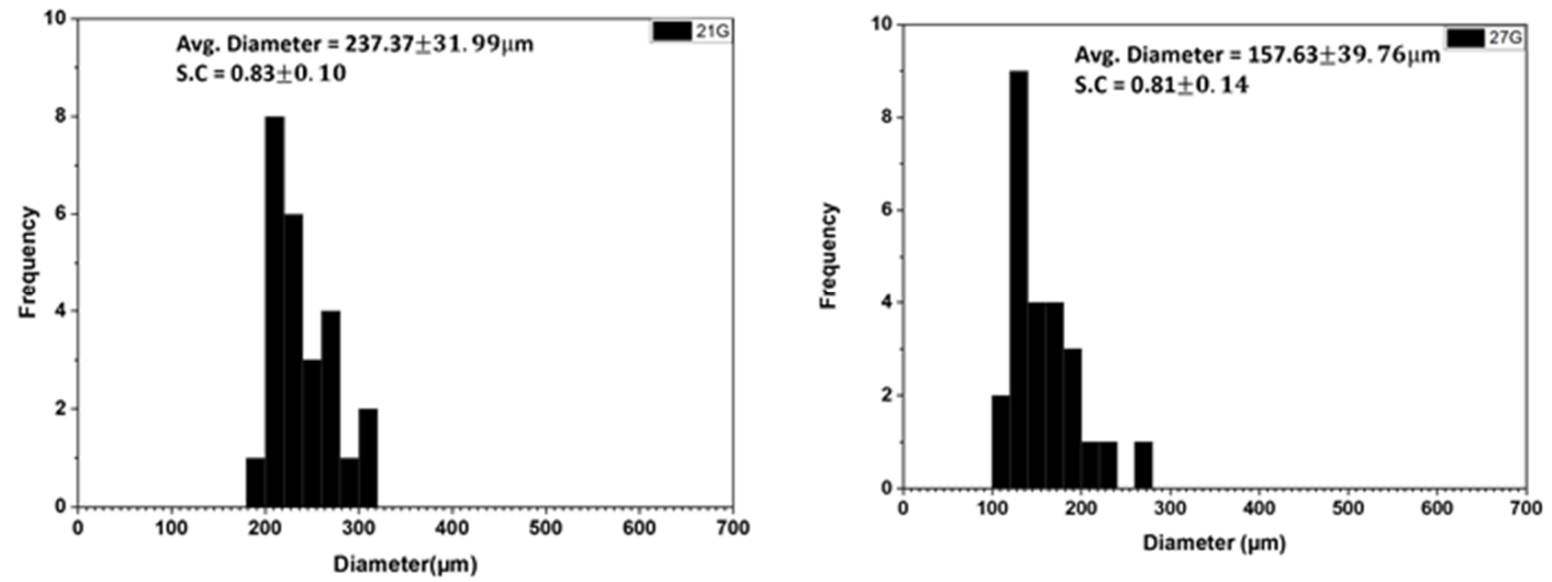

Figure 5. Monothetic Analysis of 25 random calcium alginate microcapsules electrosprayed through varying needle diameter.

Generally, according to all previously studied parameters affecting on microcapsules formulation, the investigations showed normal behaviors for most studied parameters, although some deviations from the general trends of other studied variables on capsule size and sphericity were observed, depicting that the variable interactivity influenced capsule size and sphericity.

\subsection{ANOVA and Model Generation}

The OFAT analysis of the effects of the various parameters showed varying inconsistencies, which can only be explained by analyzing the variable parameter interactions and the degree of their effects on size and sphericity.

The model, a polynomial of the second order, was used to evaluate particle size. The trials showed excellent distribution about the linear regression of the model. The Model F test was obtained as 3219.25 for capsule diameter and 253.24 for sphericity, with a $p$-value $<0.05$ as the threshold of significance of the parameters and their interaction. The lack of fit F-value for the models was obtained at 0.8006 and 0.20 for microcapsule diameter and sphericity, respectively. The non-significant lack of fit for both models was good, indicating fit models. The ANOVA table distribution is shown in Tables 3 and 4 .

Table 3. ANOVA for Quadratic Model of Microcapsule Diameter.

\begin{tabular}{cccccc}
\hline Source & Sum of Squares & df & Mean Square & F-Value & $p$-Value \\
\hline $\begin{array}{c}\text { Model } \\
\text { A }\left(\mathrm{X}_{1}\right) \text {-sodium }\end{array}$ & $5.212 \times 10^{6}$ & 20 & $2.606 \times 10^{5}$ & 3219.25 & $<0.0001$ \\
alginate & $57,254.67$ & 1 & $57,254.67$ & 707.30 & $<0.0001$ \\
concentration & & & & \\
$\mathrm{B}\left(\mathrm{X}_{2}\right)$-Flowrate & 424.16 & 1 & 424.16 & 5.24 & 0.0295 \\
$\mathrm{C}\left(\mathrm{X}_{3}\right)$-Needle Size & $2.153 \times 10^{6}$ & 1 & $2.153 \times 10^{6}$ & $26,602.98$ & $<0.0001$ \\
$\mathrm{D}\left(\mathrm{X}_{4}\right)$-Voltage & $9.512 \times 10^{5}$ & 1 & $9.512 \times 10^{5}$ & $11,751.21$ & $<0.0001$ \\
$\mathrm{E}\left(\mathrm{X}_{5}\right)$-Calcium & & & & \\
chloride & 3.13 & 1 & 3.13 & 0.0386 & 0.8456 \\
concentration & & & & \\
$\mathrm{AB}\left(\mathrm{X}_{1} \mathrm{X}_{2}\right)$ & 320.66 & 1 & 320.66 & 3.96 & 0.0561 \\
$\mathrm{AC}\left(\mathrm{X}_{1} \mathrm{X}_{3}\right)$ & 4144.28 & 1 & 4144.28 & 51.20 & $<0.0001$ \\
$\mathrm{AD}\left(\mathrm{X}_{1} \mathrm{X}_{4}\right)$ & 6493.40 & 1 & 6493.40 & 80.22 & $<0.0001$ \\
$\mathrm{AE}\left(\mathrm{X}_{1} \mathrm{X}_{5}\right)$ & 4650.78 & 1 & 4650.78 & 57.45 & $<0.0001$ \\
$\mathrm{BC}\left(\mathrm{X}_{2} \mathrm{X}_{3}\right)$ & 4288.83 & 1 & 4288.83 & 52.98 & $<0.0001$ \\
$\mathrm{BD}\left(\mathrm{X}_{2} \mathrm{X}_{4}\right)$ & 3390.96 & 1 & 3390.96 & 41.89 & $<0.0001$ \\
$\mathrm{CD}\left(\mathrm{X}_{3} \mathrm{X}_{4}\right)$ & $76,976.49$ & 1 & $76,976.49$ & 950.94 & $<0.0001$ \\
\hline
\end{tabular}


Table 3. Cont.

\begin{tabular}{cccccc}
\hline Source & Sum of Squares & df & Mean Square & F-Value & $p$-Value \\
\hline $\mathrm{CE}\left(\mathrm{X}_{3} \mathrm{X}_{5}\right)$ & 1514.59 & 1 & 1514.59 & 18.71 & 0.0002 \\
$\mathrm{DE}\left(\mathrm{X}_{4} \mathrm{X}_{5}\right)$ & 3414.89 & 1 & 3414.89 & 42.19 & $<0.0001$ \\
$\mathrm{~A}^{2}\left(\mathrm{X}_{1}^{2}\right)$ & 1566.25 & 1 & 1566.25 & 19.35 & 0.0001 \\
$\mathrm{~B}^{2}\left(\mathrm{X}_{2}^{2}\right)$ & 647.87 & 1 & 647.87 & 8.00 & 0.0084 \\
$\mathrm{C}^{2}\left(X_{3}^{2}\right)$ & 1459.96 & 1 & 1459.96 & 18.04 & 0.0002 \\
Residual & 2347.49 & 29 & 80.95 & & \\
Lack of Fit & 1568.52 & 22 & 71.30 & 0.6407 & 0.8006 \\
Pure Error & 778.96 & 7 & 111.28 & & \\
Cor Total & $5.214 \times 10^{6}$ & 49 & & & \\
\hline
\end{tabular}

Table 4. ANOVA for Quadratic Model of Sphericity coefficient.

\begin{tabular}{llllll}
\hline Source & Sum of Squares & df & Mean Square & F-Value & $p$-Value \\
\hline Model & 1.69 & 20 & 0.0847 & 253.24 & $<0.0001$ \\
$\mathrm{~A}\left(\mathrm{X}_{1}\right)$-sodium & 0.4518 & 1 & 0.4518 & 1350.64 & $<0.0001$ \\
alginate concentration & 0.4692 & 1 & 0.4692 & 1402.38 & $<0.0001$ \\
$\mathrm{~B}\left(\mathrm{X}_{2}\right)$-Flowrate & 0.0165 & 1 & 0.0165 & 49.20 & $<0.0001$ \\
$\mathrm{C}\left(\mathrm{X}_{3}\right)$-Needle Size & 0.0222 & 1 & 0.0222 & 66.32 & $<0.0001$ \\
$\mathrm{D}\left(\mathrm{X}_{4}\right)$-Voltage & 0.0014 & 1 & 0.0014 & 4.28 & 0.0475 \\
$\mathrm{E}\left(\mathrm{X}_{5}\right)-$-Calcium & 1 & 0.4440 & 1327.09 & $<0.0001$ \\
chloride concentration & 0.4440 & 1 & 0.0070 & 21.02 & $<0.0001$ \\
$\mathrm{AB}\left(\mathrm{X}_{1} \mathrm{X}_{2}\right)$ & 0.0070 & 1 & 0.0021 & 6.36 & 0.0174 \\
$\mathrm{AC}\left(\mathrm{X}_{1} \mathrm{X}_{3}\right)$ & 0.0021 & 1 & 0.0041 & 12.21 & 0.0015 \\
$\mathrm{AE}\left(\mathrm{X}_{1} \mathrm{X}_{5}\right)$ & 0.0041 & 1 & 0.0027 & 8.15 & 0.0079 \\
$\mathrm{BC}\left(\mathrm{X}_{2} \mathrm{X}_{3}\right)$ & 0.0027 & 1 & 0.0080 & 23.95 & $<0.0001$ \\
$\mathrm{BD}\left(\mathrm{X}_{2} \mathrm{X}_{4}\right)$ & 0.0080 & 1 & 0.0072 & 21.54 & $<0.0001$ \\
$\mathrm{BE}\left(\mathrm{X}_{2} \mathrm{X}_{5}\right)$ & 1 & 0.0040 & 11.90 & 0.0017 \\
$\mathrm{CE}\left(\mathrm{X}_{3} \mathrm{X}_{5}\right)$ & 0.0072 & 1 & 0.0179 & 53.42 & $<0.0001$ \\
$\mathrm{DE}\left(\mathrm{X}_{4} \mathrm{X}_{5}\right)$ & 0.0040 & 1 & 0.0089 & 26.60 & $<0.0001$ \\
$\mathrm{~A}^{2}\left(\mathrm{X}_{1}^{2}\right)$ & 0.0179 & 1 & 0.0032 & 9.57 & 0.0044 \\
$\mathrm{~B}^{2}\left(\mathrm{X}_{2}^{2}\right)$ & 0.0089 & 29 & 0.0003 & & \\
$\mathrm{D}^{2}\left(\mathrm{X}_{4}{ }^{2}\right)$ & 0.0032 & 22 & 0.0004 & 1.83 & 0.2093 \\
Residual & 0.0097 & 0.0002 & & \\
Lack of Fit & 0.0083 & & & & \\
Pure Error & 0.0014 & 1.70 & & & \\
Cor Total & & & &
\end{tabular}

The equations governing the particle diameter and sphericity coefficient determination were given as shown in Equations (4) and (5):

$$
\begin{aligned}
& \operatorname{Diameter}(\mu \mathrm{m})=535.082+48.424 \mathrm{X}_{1}-4.273 \mathrm{X}_{2}-290.056 \mathrm{X}_{3}-201.952 \mathrm{X}_{4}+0.349 \mathrm{X}_{5} \\
& -16.796 \mathrm{X}_{1} \mathrm{X}_{3}+17.214 \mathrm{X}_{1} \mathrm{X}_{4}+18.575 \mathrm{X}_{1} \mathrm{X}_{5}-14.625 \mathrm{X}_{2} \mathrm{X}_{3} \\
& -12.622 X_{2} X_{4}+72.806 X_{3} X_{4}-8.576 X_{3} X_{5}+15.618 X_{4} X_{5}-25.467 X_{1}^{2} \\
& +12.962 X_{2}^{2}+27.321 X_{3}^{2} \\
& \text { Sphericity }=0.821-0.136 \mathrm{X}_{1}-0.142 \mathrm{X}_{2}-0.025 \mathrm{X}_{3}-0.031 \mathrm{X}_{4}-0.007 \mathrm{X}_{5}-0.146 \mathrm{X}_{1} \mathrm{X}_{2} \\
& +0.021 X_{1} X_{3}-0.013 X_{1} X_{5}+0.014 X_{2} X_{3}+0.011 X_{2} X_{4}+0.020 X_{2} X_{5} \\
& -0.086 X_{3} X_{5}+0.0169-0.086 X_{1}^{2}-0.048 X_{2}^{2}+0.034 X_{4}^{2}
\end{aligned}
$$

The particle size diameter and sphericity coefficient equations factored all linear parameters, important and possibly important quadratic effects and interrelationships.

\subsubsection{Linear Variable Effect on Microcapsule Size and Sphericity}

The perturbation graphs in Figure 6 depict the linear relationship between the studied independent parameters and their responses. The graph summed up the parameter effect 
of the independent variables and how they affect the model. With respect to microcapsule diameter, in Figure 6a the biggest contributor to size increment was needle size, followed closely by voltage. A positive deviation from the reference point for voltage and needle size produced smaller microcapsules. A reduction in the needle gauge and voltage decrement resulted in larger particle sizes. Alginate concentration was the next important parameter, an increment of which results in larger microcapsule sizes. However, the contributions of increasing alginate concentration on particle size plateau, and become insignificant at very high alginate concentrations. Flowrate and calcium chloride concentration had the least effect on microcapsule size. While their effect is noticeable, the overall contribution to the model, compared to the other parameters, is small.
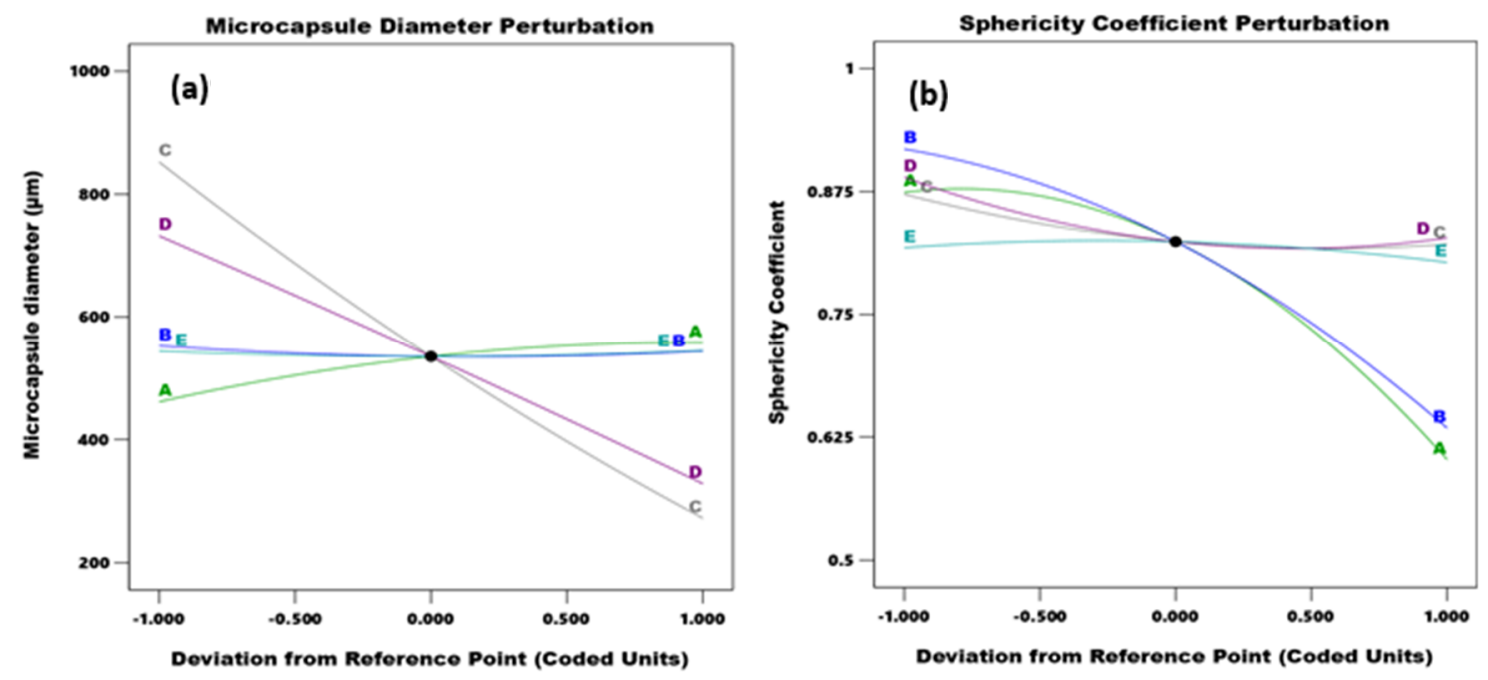

Figure 6. Perturbation summary of independent parameters (A-Alginate concentration; BFlowrate; C-Needle Size; D-Voltage; $\mathrm{E}-\mathrm{CaCl}_{2}$ concentration) on (a) Microcapsule Diameter and (b) Sphericity Coefficient.

The effect of the parameter on the sphericity coefficient is summarized in Figure $6 \mathrm{~b}$. Alginate concentration and flowrate were the biggest contributors to sphericity from the model. More spherical capsules were observed with decreasing the flowrate and alginate concentration. Spherical microcapsules can be formed at small and large needle sizes, as shown in Figures 5a,b and 6. The effect of calcium chloride concentration was small. As calcium chloride concentration increases, the graph line begins to taper at the end, explaining that a further increment in calcium chloride concentration could lead to less sphericity. Other parameters could influence the results observed in Figure 4. The increment in voltage leads to less spherical microcapsules.

\subsubsection{Effect of Independent Variable Interaction on Microcapsule Particle Size and Sphericity}

The effects of the independent variable interaction on the capsule size and sphericity coefficient response parameters are summarized in Figures 7 and 8. In Figure 7a, capsule size decreased with decreasing needle size and alginate concentration. Low viscous alginate solution through a smaller needle diameter favored the formation of smaller microcapsules. Microcapsule diameter increased with increasing sodium alginate concentration, even at a smaller needle diameter. In another investigation [15], a similar trend and effect of viscosity and needle size effect on capsule diameter was observed. Effect on sphericity of the interaction between alginate concentration and needle size was observed in Figure 8b. The more effective parameter was the sodium alginate concentration. Increasing the alginate concentration and pushing through a small-sized needle created elongated and stretched capsules. A third parameter that affects both alginate concentration and needle size is flowrate. Highly viscous alginate solutions electrosprayed through smaller needle diameters have high sphericity if pumped at a very low flowrate [15]. Voltage and alginate 
concentration effect on diameter is shown in Figure $7 \mathrm{~b}$. Microcapsule diameter increased with decreasing alginate concentration and increasing voltage. However, the voltage was the dominant parameter, accounting for the steeper change in microcapsule diameter.
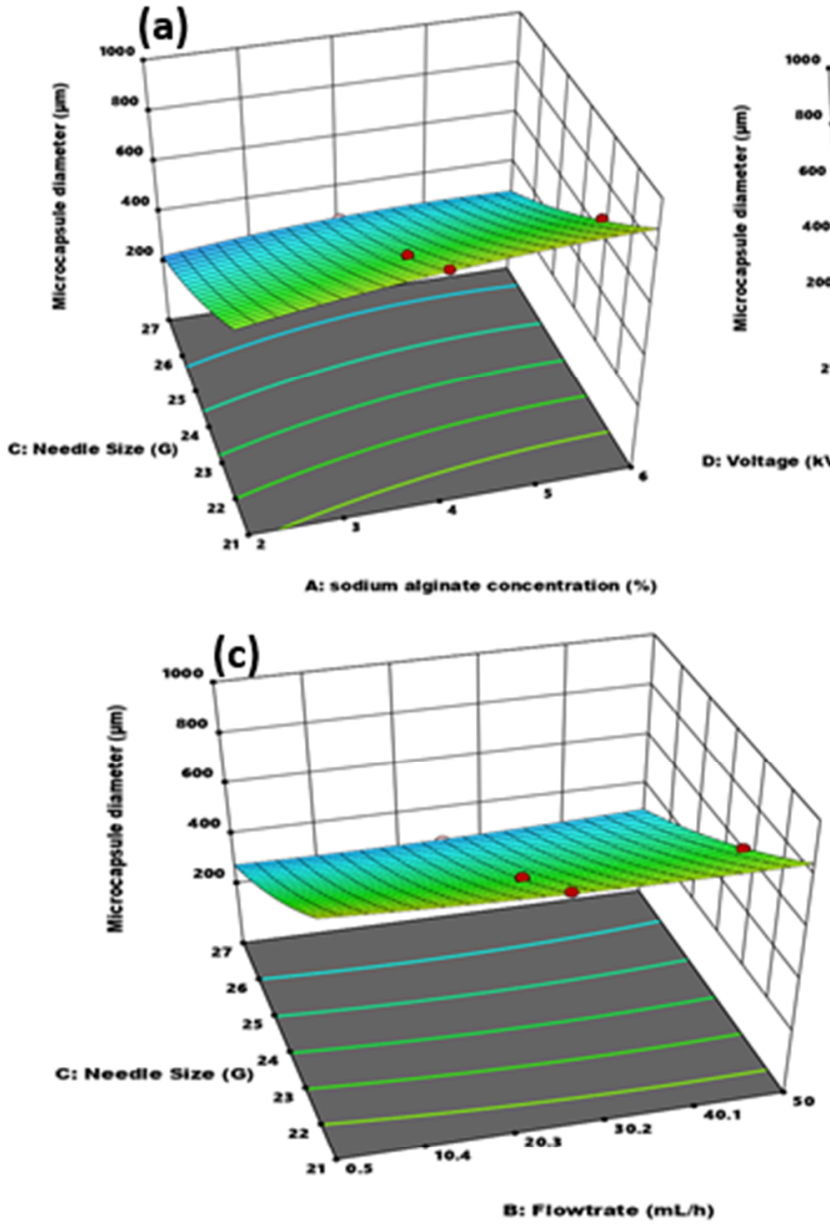

(e)

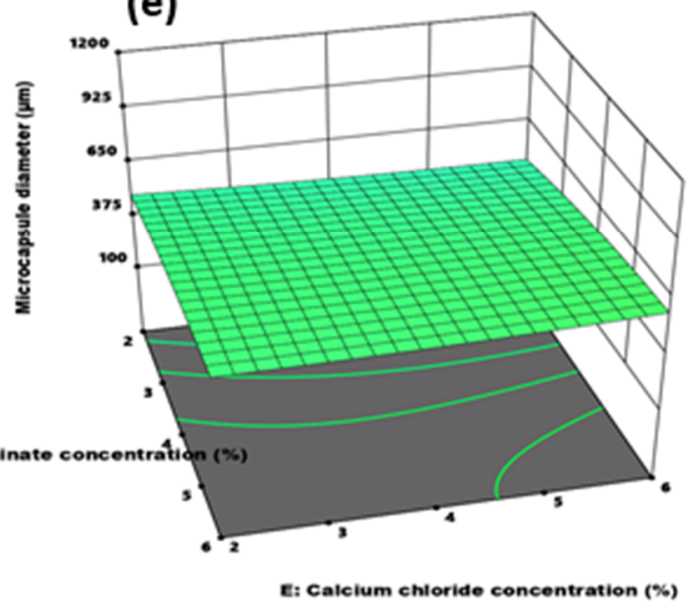

(b)
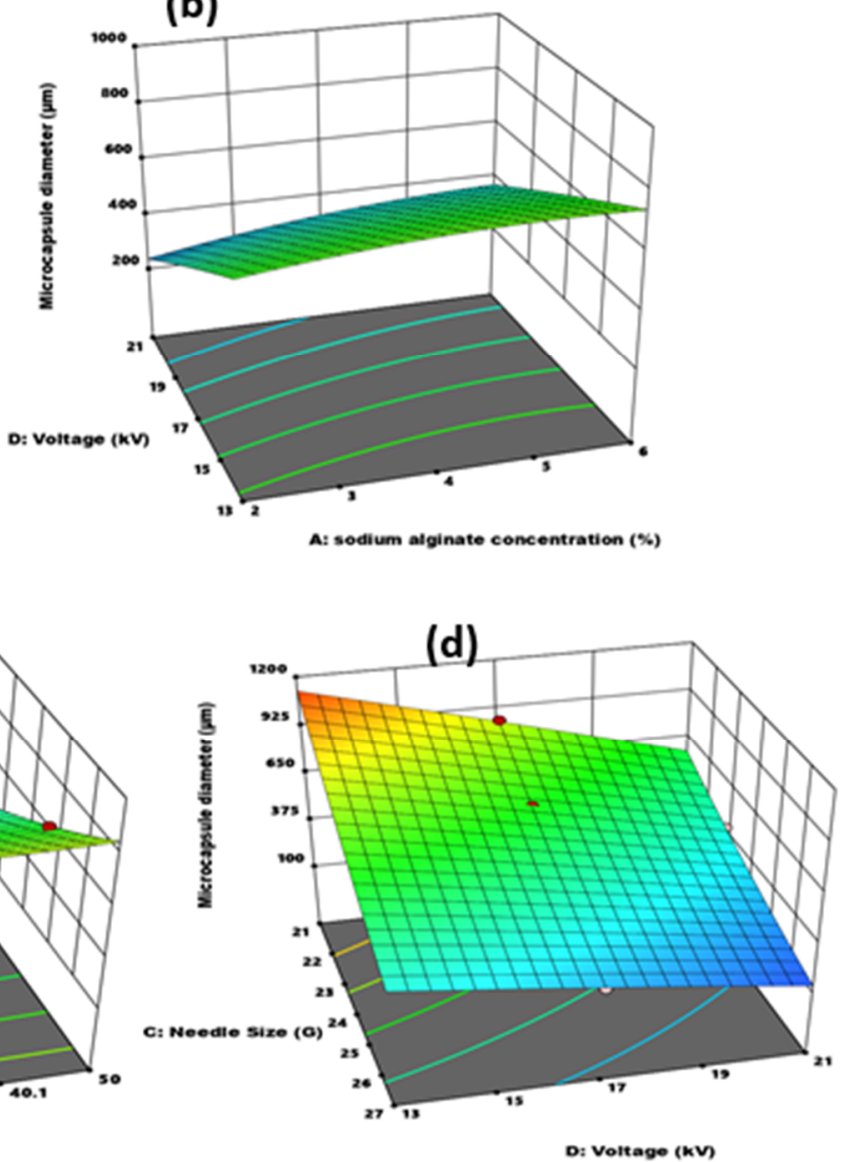

(f)

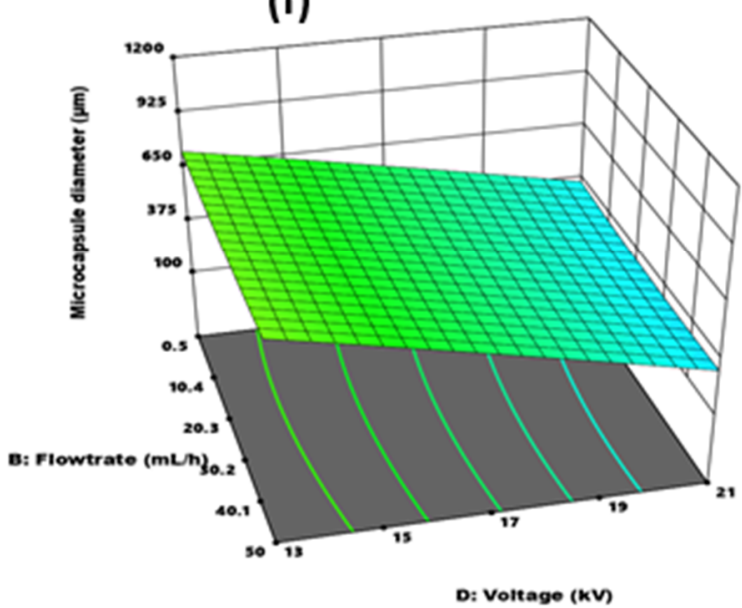

Figure 7. 3D Surface plots of varying independent parameter interactions. (a) Alginate concentration and needle size; (b) voltage and alginate concentration; (c) needle size and flowrate; (d) voltage and needle size; (e) alginate concentration; (f) voltage and flowrate and their effect on microcapsule diameter. 


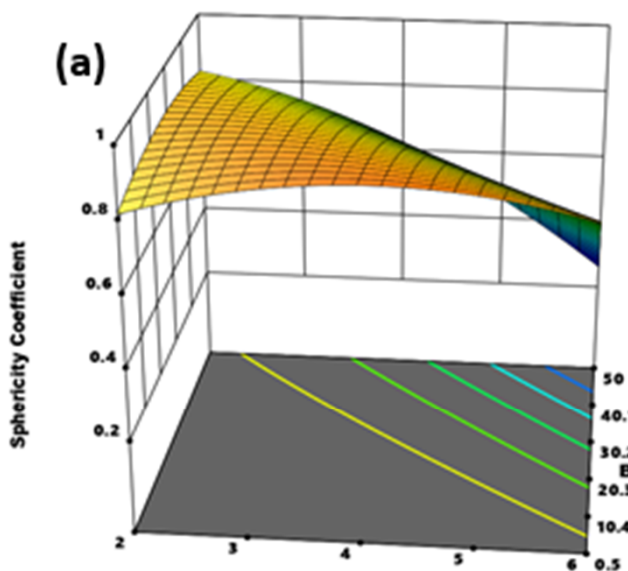

A: sodium alginate concentration (\%)
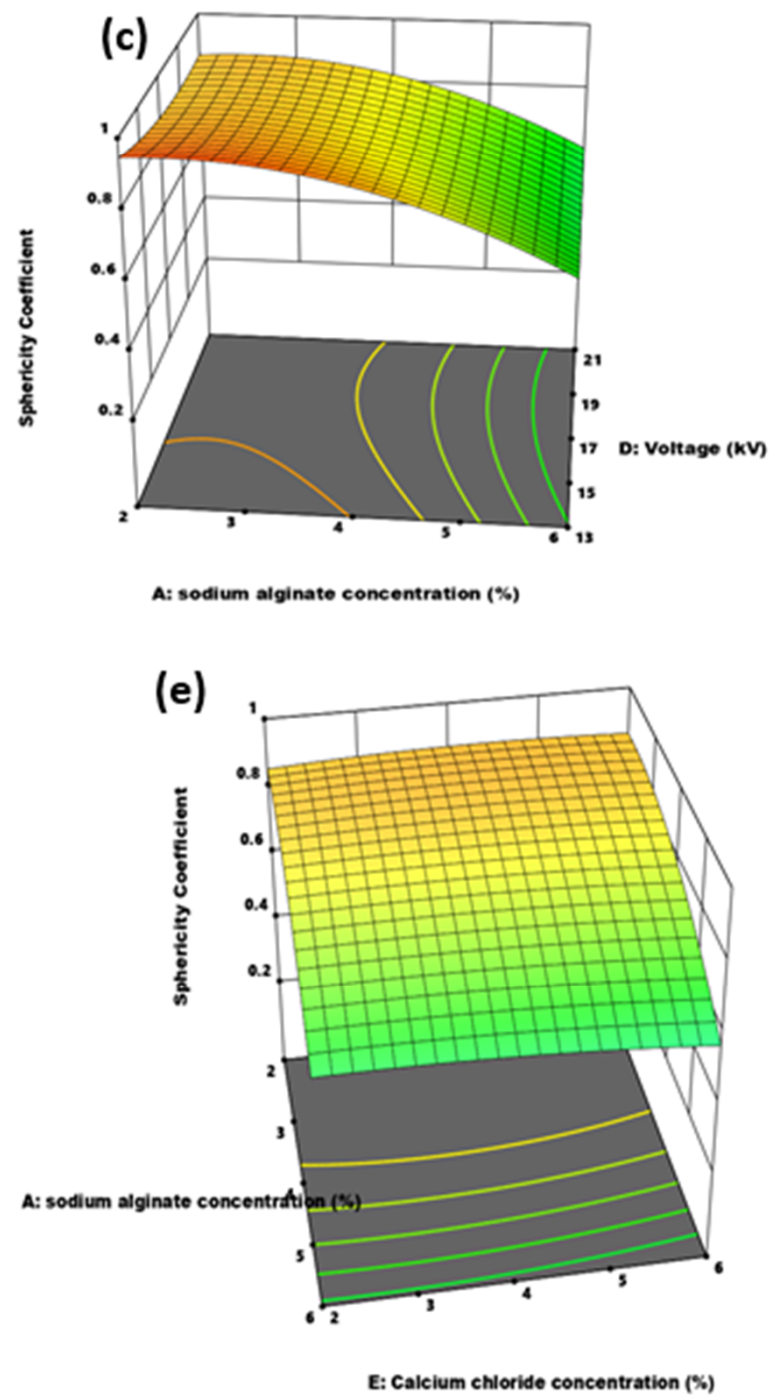
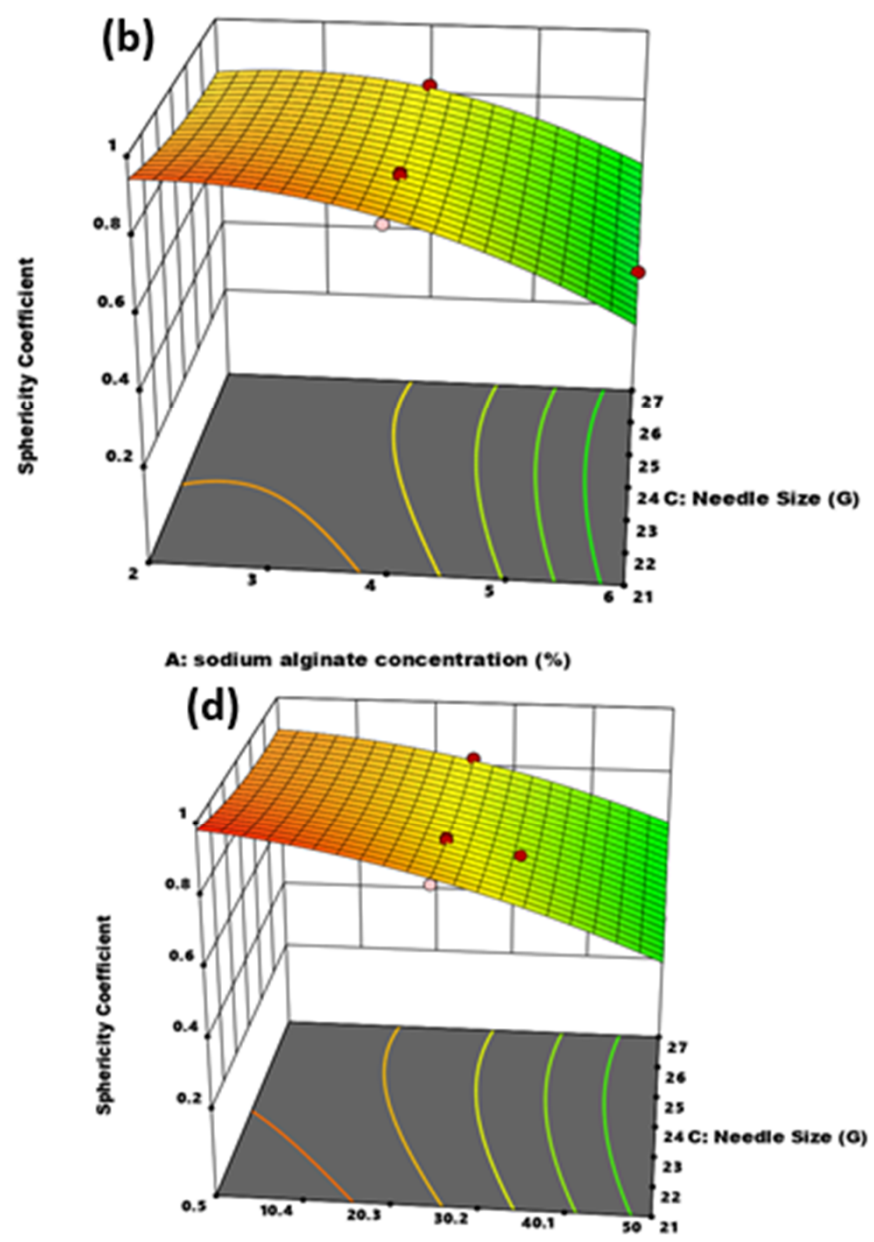

B: Flowtrate $(\mathrm{mL} / \mathrm{h}$

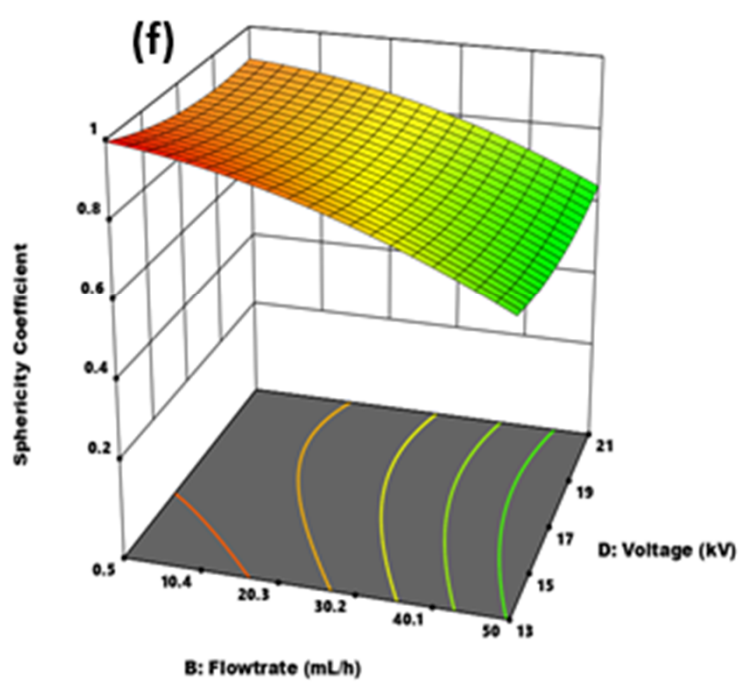

Figure 8. $3 \mathrm{D}$ surface plot of independent variable interactions. (a) Alginate concentration and flowrate; (b) alginate concentration and needle size; (c) alginate concentration and voltage; (d) flowrate and needle size; (e) alginate and $\mathrm{CaCl}_{2}$ concentration; (f) flowrate and voltage and their effect on sphericity. 
Figure $8 \mathrm{c}$ showed sodium alginate concentration to be an important parameter in sphericity determination. The best sphericity was obtained at the lowest voltage and alginate concentration. Low concentrated alginate solutions are quickly broken off by increasing the voltage, leading to smaller and more spherical capsules in the jets electrosprayed into the crosslinker. As the voltage increases, the frequency of the breakage increases until a thin continuous line of fiber formation starts. Thus, an increase in voltage favored small size and less sphericity. The increase in polymer concentration leads to difficulty in breaking the droplet at the tip. The viscous forces prevent a clean break at the tip, leading to tailed-shaped microcapsules resembling tear-, pear- and egg-shaped microcapsules [18], as seen in Figure 3c.

From Figure 7, the flowrate and needle size interaction effects were observed, with respect to capsule diameter. Lower flowrate and smaller needle diameter favored smaller capsule size. The pump rate influences the amount of fluid pushed through the needle diameter, and in effect, the bubble size formed at the tip. A higher flowrate is proportionate to a higher bubble diameter formed at the needle tip, and as such, an overall capsule diameter. However, the dominant parameter was needle size instead of flowrate from the Figure. Observing the sphericity coefficient for flowrate and needle size in Figure 8d, low flowrate and large needle diameter favored better sphericity. The interaction of the two most influential parameters on capsule size was observed in Figure 7d. A steep decrease in size with increasing voltage and decreasing needle diameter showed a strong parameter variation effect. The effect of voltage is felt at the tip of the needle, and as such, the influence of voltage on particle size is on the bubble of the polymer at the nozzle. The droplet size at the tip of the needle is greatly influenced by needle size. If a small bubble-sized polymer is formed at the tip, the effect of voltage is then applied to reduce the size further. The needle size greatly influences the amount of fluid available at the tip for voltage to act on. It can be observed from the Figure that the smallest size was at $21 \mathrm{kV}$ and $27 \mathrm{G}$, showing that needle size is the more effective of both parameters.

In Figure 7e, calcium chloride and alginate concentrations had minor effects on particle size. The Alginate concentration was the slightly dominant parameter. Figure $7 \mathrm{f}$ compared voltage and flowrate on capsule diameter. Smaller size capsules were formed at a low flowrate. However, the effect of flowrate in the presence of voltage was inconsequential, as the major changes in diameter occurred with voltage variation, making it the more important and effective parameter of the two.

Sphericity improves with a lower feed rate and increasing alginate concentration, as shown in Figure 8a. The effect of flowrate at low viscosity is almost negligible on sphericity, with slightly more spherical capsules observed at higher flowrates. The lower sphericity coefficients were recorded at the highest alginate concentration and highest flowrates. In Figure $8 \mathrm{e}, \mathrm{f}$, the effect of calcium chloride and sodium alginate concentration and flowrate and voltage on sphericity were observed. In Figure 8e, alginate concentration remained the dominant parameter, and flowrate was the important parameter in Figure 8f. While high voltage is an important parameter for smaller-sized microcapsules, the inverse is true for sphericity, as shown in Figure 8f.

Finally, the numerical optimization of the calcium alginate microcapsules size and sphericity was conducted from the Design-Expert Software. Overall, particle size reduction was given more importance over the sphericity of the microcapsule. The optimum parameter was selected at an alginate concentration of $2.013 w / v$, with a flowrate of $0.560 \mathrm{~mL} / \mathrm{h}$, a needle size of $27 \mathrm{G}$ and a $2.024 \mathrm{w} / \mathrm{v}$ calcium chloride concentration. The predicted size was $92.586 \mu \mathrm{m}$, with a sphericity coefficient of 0.771 , with a $94.54 \%$ desirability based on the importance given to the independent variables.

\section{Conclusions}

This study analyzed the electrospraying process and the governing parameters regarding the size and sphericity of the produced calcium alginate microcapsules. The independent process variables were studied, and the interaction between the variables and 
their correlations to microcapsule diameter and sphericity response were measured. The microcapsule diameter was significantly influenced by the needle size, voltage and alginate concentration. Similar parameter influence was observed regarding sphericity, with flowrate being an additional significant influencing independent parameter. Accordingly, an accurate model for predicting the optimized parameters was successfully developed. Furthermore, variable interactions on response values were also evaluated, showing strong interrelationships on response parameters. As such, OFAT experimental processes are not enough to fully explain the optimization of the electrospray process. Optimized parameters were obtained with respect to the important response parameter, and the optimization was biased towards forming a smaller size with appreciable sphericity.

Author Contributions: Conceptualization, H.N. and M.E.; methodology, J.A.; validation, J.A.; formal analysis, J.A.; investigation, J.A.; data curation, J.A., H.N., A.Z., M.E. and T.Y.; writing—original draft preparation, J.A.; writing-review and editing, J.A., H.N., A.Z., M.E. and T.Y.; and supervision, H.N., A.Z., M.E. and T.Y. All authors have read and agreed to the published version of the manuscript.

Funding: This research received no external funding.

Institutional Review Board Statement: Not applicable.

Informed Consent Statement: Not applicable.

Data Availability Statement: Not applicable.

Acknowledgments: The first author, J.A. thanks the Japan International Cooperation Agency (JICA) for providing a fully funded Scholarship to study his MSc.at Egypt-Japan University of Science and Technology, Egypt. The authors appreciated the project of JICA to Kyushu university for covering the publication fees.

Conflicts of Interest: The authors declare no conflict of interest.

\section{References}

1. Pawar, S.N.; Edgar, K.J. Alginate Derivatization: A Review of Chemistry, Properties and Applications. Biomaterials 2012, 33, 3279-3305. [CrossRef] [PubMed]

2. Sharmila, A.; Mardera, M.S.; Soundarya, H.P.; Shreyas, M. Treatment of Textile Wastewater Using Sodium Alginate Beads. J. Phys. Conf. Ser. 2021, 1979, 012005. [CrossRef]

3. Yan, M.; Shi, J.; Liu, L.; Zhu, H.; Tang, S.; Zhou, G.; Zeng, J.; Zhang, H.; Yu, Y.; Guo, J. Preparation of High-Strength and High-Toughness Sodium Alginate Fibers Based on the Study of Multi-Ion Diffusion Kinetics in a Low Temperature Dissolution System. New J. Chem. 2021, 45, 5981-5991. [CrossRef]

4. Liu, Z.; Chen, X.; Guo, H. Preparation and Properties of a Novel Sodium Alginate Microcapsule. J. Phys. Conf. Ser. 2021, 1893. [CrossRef]

5. Atanase, L.I. Micellar Drug Delivery Systems Based on Natural Biopolymers. Polymers 2021, 13, 477. [CrossRef] [PubMed]

6. Wang, X.; Wang, W.; Liu, A.; Fan, W.J.; Ding, R.; Tian, H.; Han, P.; Li, W.H. Self-Healing and Anti-Corrosion Performances of 1, 2, 4-Triazole Modified Nano-Silica Hydrogels. Colloids Interface Sci. Commun. 2018, 27, 11-17. [CrossRef]

7. Wen, J.; Lei, J.; Chen, J.; Gou, J.; Li, Y.; Li, L. An Intelligent Coating Based on PH-Sensitive Hybrid Hydrogel for Corrosion Protection of Mild Steel. Chem. Eng. J. 2020, 392, 123742. [CrossRef]

8. Sun, J.; Wang, Y.; Tian, L.; Pan, C. Study on Preparation Technology of Self-Healing Micro-Nano Capsule Based on Calcium Alginate. In Proceedings of the 2018 IEEE International Conference on Manipulation, Manufacturing and Measurement on the Nanoscale (3M-NANO), Hangzhou, China, 13-17 August 2018; pp. 151-154.

9. Costa, A.B.; Graham Cooks, R. Simulated Splashes: Elucidating the Mechanism of Desorption Electrospray Ionization Mass Spectrometry. Chem. Phys. Lett. 2008, 464, 1-8. [CrossRef]

10. Khosroyar, S. Ferric-Saccharate Capsulation with Alginate Coating Using the Emulsification Method. Afr. J. Microbiol. Res. 2012, 6, 2455-2461.

11. Poncelet, D.; Lencki, R.; Beaulieu, C.; Halle, J.P.; Neufeld, R.J.; Fournier, A. Production of Alginate Beads by Emulsification/Internal Gelation. I. Methodology. Appl. Microbiol. Biotechnol. 1992, 38, 39-45. [CrossRef]

12. Uyen, N.T.T.; Hamid, Z.A.A.; Tram, N.X.T.; Ahmad, N. Fabrication of Alginate Microspheres for Drug Delivery: A Review. Int. J. Biol. Macromol. 2020, 153, 1035-1046. [CrossRef] [PubMed]

13. Zhou, Q.; Kang, H.; Bielec, M.; Wu, X.; Cheng, Q.; Wei, W.; Dai, H. Influence of Different Divalent Ions Cross-Linking Sodium Alginate-Polyacrylamide Hydrogels on Antibacterial Properties and Wound Healing. Carbohydr. Polym. 2018, 197, 292-304. [CrossRef] [PubMed] 
14. Grant, G.T.; Morris, E.R.; Rees, D.A.; Smith, P.J.C.; Thom, D. Biological Interactions between Polysaccharides and Divalent Cations: The Egg-Box Model. FEBS Lett. 1973, 32, 195-198. [CrossRef]

15. Klokk, T.I.; Melvik, J.E. Controlling the Size of Alginate Gel Beads by Use of a High Electrostatic Potential. J. Microencapsul. 2002, 19, 415-424. [CrossRef]

16. Elkady, M.; Hassan, H.S.; Hashim, A. Immobilization of magnetic nanoparticles onto amine-modified nano-silica gel for copper ions remediation. Materials 2016, 9, 460. [CrossRef] [PubMed]

17. Cassidy, M.B.; Lee, H.; Trevors, J.T. Environmental Applications of Immobilized Microbial Cells: A Review. J. Ind. Microbiol. 1996, 16, 79-101. [CrossRef]

18. Lee, B.B.; Ravindra, P.; Chan, E.S. Size and Shape of Calcium Alginate Beads Produced by Extrusion Dripping. Chem. Eng. Technol. 2013, 36, 1627-1642. [CrossRef]

19. Partovinia, A.; Vatankhah, E. Experimental Investigation into Size and Sphericity of Alginate Micro-Beads Produced by Electrospraying Technique: Operational Condition Optimization. Carbohydr. Polym. 2019, 209, 389-399. [CrossRef]

20. Nedović, V.A.; Obradović, B.; Leskošek-Čukalović, I.; Trifunović, O.; Pešić, R.; Bugarski, B. Electrostatic Generation of Alginate Microbeads Loaded with Brewing Yeast. Process Biochem. 2001, 37, 17-22. [CrossRef]

21. Zakeri, M.; Moghadam, H.; Samimi, A.; Mohebbi-Kalhori, D. Optimization of Calcium Alginate Beads Production by Electrospray Using Response Surface Methodology. Mater. Res. Express, 2019, 6, 095412. [CrossRef]

22. Poncelet, D. Production of Alginate Beads by Emulsification/Internal Gelation. Ann. N. Y. Acad. Sci. 2001, 944, 74-82. [CrossRef] [PubMed]

23. Mehregan Nikoo, A.; Kadkhodaee, R.; Ghorani, B.; Razzaq, H.; Tucker, N. Controlling the Morphology and Material Characteristics of Electrospray Generated Calcium Alginate Microhydrogels. J. Microencapsul. 2016, 33, 605-612. [CrossRef] [PubMed]

24. Lotfipour, F.; Mirzaeei, S.; Maghsoodi, M. Evaluation of the Effect of Cacl2 and Alginate Concentrations and Hardening Time on the Characteristics of Lactobacillus Acidophilus Loaded Alginate Beads Using Response Surface Analysis. Adv. Pharm. Bull. 2012, 2, 71-78. [PubMed]

25. Shi, P.; He, P.; Teh, T.K.H.; Morsi, Y.S.; Goh, J.C.H. Parametric Analysis of Shape Changes of Alginate Beads. Powder Technol. 2011, 210, 60-66. [CrossRef]

26. Zhang, S.; Campagne, C.; Salaün, F. Influence of Solvent Selection in the Electrospraying Process of Polycaprolactone. Appl. Sci. 2019, 9, 402. [CrossRef]

27. Fukui, Y.; Maruyama, T.; Iwamatsu, Y.; Fujii, A.; Tanaka, T.; Ohmukai, Y.; Matsuyama, H. Preparation of Monodispersed Polyelectrolyte Microcapsules with High Encapsulation Efficiency by an Electrospray Technique. Colloids Surfaces A Physicochem. Eng. Asp. 2010, 370, 28-34. [CrossRef]

28. Huang, K.S.; Yang, C.H.; Lin, Y.S.; Wang, C.Y.; Lu, K.; Chang, Y.F.; Wang, Y.L. Electrostatic Droplets Assisted Synthesis of Alginate Microcapsules. Drug Deliv. Transl. Res. 2011, 1, 289-298. [CrossRef] [PubMed]

29. Moghaddam, M.K.; Mortazavi, S.M.; Khaymian, T. Micro/Nano-Encapsulation of a Phase Change Material by Coaxial Electrospray Method. Iran. Polym. J. 2015, 24, 759-774. [CrossRef] 